\title{
Cryopreservation of Adipose Tissue for Cosmetic Treatment of HIV Related Facial Lipoatrophy is Underused
}

\section{Abstract}

Few infectious diseases have the social stigma or the emotional power that is often associated with HIV. Many AIDS patients suffer from depression or societal ostracization partly due to the fact that they look different over time. Banking of adipose tissue early after diagnosis for subsequent autologous use years later can offer patients a safe and affordable surgical option for reversing the changes in facial appearance and social stigma that associate with HIV status.

Keywords: AIDS, Adipose tissue; Cryopreservation; Facial lipoatrophy

Received: November 10, 2015; Accepted: November 13, 2015; Published: November 20, 2015

\section{Editorial}

Few infectious diseases have the social stigma or the emotional power that is often associated with HIV. The psychological impact of any disease can be its own difficult, and occasionally insurmountable, hurdle that has very little to do with science or medicine. However, HIV infection seems to have taken on the mantle of a disease with the greatest overall social impact. Over more than three decades of research vast new understanding of the infection and disease progression has taken place. Current states of knowledge have allowed the development of drug cocktails (HAART therapy) that keep a large fraction of morbidity and mortality at bay. But as HIV+ patients live longer and better lives, they must still contend with prejudice and stigma that sometimes associates with disease status. This is often due to the simple fact that HIV+ people look like HIV+ people. As the disease progresses, elements of HIV associated lipodystrophy can change the individuals appearance. Banking of adipose tissue early after diagnosis for subsequent autologous use years later can offer patients a safe and affordable surgical option for reversing the changes in facial appearance and social stigma that associate with HIV status.

A variety of lipodystrophies exist with a variety of etiologies. For HIV+ patients, it can mean differences in fat content over various body areas including back, legs, face, abdomen and other locales. Lypodystrophy, in general, can be more accurately refined to facial lipoatrophy for purposes of this article. As new drugs have come on line, some HIV associated lipodystrophies have been

\author{
Michael Badowski \\ Arizona Biorepository and Laboratory \\ Exchange, the University of Arizona, USA
}

Corresponding author: Michael Badowski

Arizona Biorepository and Laboratory Exchange, the University of Arizona, USA.

badowski@email.arizona.edu

Tel: 1-520-626-5125

Citation: Badowski M. Cryopreservation of Adipose Tissue for Cosmetic Treatment of HIV Related Facial Lipoatrophy is Underused.

J Infec Dis Treat. 2015, 1:1. 
back and treat the face years later with stored tissue giving the HIV patient a healthier face to look at in the mirror each day.

Additionally, many AIDS patients suffer from depression partly due to the fact that they look different over time. We all age but people rarely notice our day to day aging. Every day we look in the mirror but fail to see the small daily changes. As years go by we might see a wrinkle that was not there before. We see a lone gray hair amid the brown ones. Maybe there are crow's feet about the eyes or the skin is just less firm than it was in our youth. These small changes appear over time to all of us. However, AIDS patients see more accelerated and more severe differences. Weight loss can occur rapidly in AIDS patients. These people can see themselves "wasting away" right before their own eyes. Surgical intervention using banked adipose tissue will undoubtedly help to stem depression in patients as their appearance can be vastly and rapidly improved.
Some may think that reintroduction of virus after long term disease management may be detrimental but there is no evidence to support that. There are no reports of adipose tissue serving as a reservoir for virus outside of the small amounts of residual blood after adipose harvest. Since adipose preservation protocols involve the removal of blood and interstitial fluids there is essentially no danger of a bolus of virus reintroduction at transplant.

Decades ago adipose transfer became a useful tool for cosmetic and reconstructive medicine. Today advances in regenerative medicine will find more uses for autologous adipose treatments. In the last several years cryopreservation of adipose tissue makes fat transfers all the more useful for cosmetic, reconstructive and regenerative medicine applications. It is time that these wellestablished techniques are applied to improve quality of life for the large population of people living with HIV. 